\title{
Future sea-level rise drives rocky intertidal habitat loss and benthic community change
}

\author{
Nikolas J Kaplanis ${ }^{\text {Corresp., 1, }}{ }^{2}$, Clinton Edwards ${ }^{2}$, Yoan Eynaud ${ }^{2}$, Jennifer E Smith ${ }^{2}$ \\ ${ }^{1}$ Department of Ecology and Evolutionary Biology, University of California, Santa Cruz, Santa Cruz, California, United States \\ ${ }^{2}$ Center for Marine Biodiversity and Conservation, Scripps Institution of Oceanography, University of California, San Diego, La Jolla, California, United \\ States \\ Corresponding Author: Nikolas J Kaplanis \\ Email address: nkaplanis@ucsc.edu
}

The impacts of sea-level rise (SLR) are likely to be the greatest for ecosystems that exist at the land-sea interface where small changes in sea-level could result in drastic changes in habitat availability. Rocky intertidal ecosystems possess a number of characteristics which make them highly vulnerable to changes in sea-level, yet our understanding of potential community scale responses to future sea-level scenarios is limited. Combining remotesensing with in-situ large-area imaging, we quantified habitat extent and characterized the biological community at two rocky intertidal study locations in California, USA. We then used a model-based approach to estimate how a variety of SLR scenarios would affect total habitat area, areal extent of dominant benthic space occupiers, and numerical abundance of invertebrates. Our results suggest that SLR will reduce total available rocky intertidal habitat area at our study locations, leading to an overall decrease in areal extent of dominant benthic space occupiers and a reduction in invertebrate abundances. As largescale environmental changes, such as SLR, accelerate in the next century, more extensive spatially explicit monitoring at ecologically relevant scales will be needed to visualize and quantify the impacts to biological systems. 


\section{Future sea-level rise drives rocky intertidal habitat loss and}

\section{2 benthic community change}

3

4 Nikolas J. Kaplanis ${ }^{1,2}$, Clinton B. Edwards ${ }^{1}$, Yoan Eynaud ${ }^{1}$, Jennifer E. Smith ${ }^{1}$

5

6 1. Center for Marine Biodiversity and Conservation, Scripps Institution of Oceanography,

$7 \quad$ University of California, San Diego, La Jolla, California, United States of America

8 2. Current address: Department of Ecology and Evolutionary Biology, University of California,

$9 \quad$ Santa Cruz, Santa Cruz, California, United States of America

11 Corresponding author:

12 Nikolas J. Kaplanis

13110 McAllister Way, Santa Cruz, California, 95060, United States of America

14 E-mail address: nkaplanis@ucsc.edu 


\section{Abstract}

16 The impacts of sea-level rise (SLR) are likely to be the greatest for ecosystems that exist at the

17 land-sea interface where small changes in sea-level could result in drastic changes in habitat

18 availability. Rocky intertidal ecosystems possess a number of characteristics which make them

19 highly vulnerable to changes in sea-level, yet our understanding of potential community scale

20 responses to future sea-level scenarios is limited. Combining remote-sensing with in-situ large-

21 area imaging, we quantified habitat extent and characterized the biological community at two

22 rocky intertidal study locations in California, USA. We then used a model-based approach to

23 estimate how a variety of SLR scenarios would affect total habitat area, areal extent of dominant

24 benthic space occupiers, and numerical abundance of invertebrates. Our results suggest that SLR

25 will reduce total available rocky intertidal habitat area at our study locations, leading to an

26 overall decrease in areal extent of dominant benthic space occupiers and a reduction in

27 invertebrate abundances. As large-scale environmental changes, such as SLR, accelerate in the

28 next century, more extensive spatially explicit monitoring at ecologically relevant scales will be

29 needed to visualize and quantify the impacts to biological systems.

\section{Introduction}

\section{Sea-level rise projections and potential impacts to the rocky}

\section{3 intertidal zone}

34 Sea-level rise is predicted to alter habitat availability and modify community structure in many

35 marine ecosystems (Hoegh-Guldberg \& Bruno, 2010; Nicholls \& Cazenave, 2010). Long-term 
36 monitoring of sea-level shows considerable variability among locations, but an overall rising

37 trend with recently increased rates of change at many locations (Church \& White, 2006; Mcleod

38 et al., 2010; Nicholls \& Cazenave, 2010; Rahmstorf, 2010; National Research Council, 2012;

39 Church et al., 2013; Cazenave et al., 2014; Chen et al., 2017). While estimates remain uncertain,

40 recent studies project up to 2.5 meters of SLR within the next century (Church et al., 2013;

41 Sweet et al., 2017). Such a large magnitude and rapid shift poses a substantial risk to the integrity

42 of coastal ecosystems, yet the extent to which SLR will modify the physical and ecological

43 structure of rocky coastlines remains mostly unknown (Denny \& Paine, 1998; Thompson, Crowe

44 \& Hawkins, 2002; Harley et al., 2006; Helmuth et al., 2006).

45 Certain characteristics of rocky intertidal systems make them particularly vulnerable to SLR

46 driven habitat loss (Denny \& Paine, 1998; Thompson, Crowe \& Hawkins, 2002; Harley et al.,

47 2006; Helmuth et al., 2006). When backed by steep cliffs or anthropogenic structures, as is the

48 case on the majority of coastlines globally (Emery \& Kuhn, 1982), many rocky shores are

49 expected to experience "coastal squeeze" - a general narrowing of the extent of the intertidal

50 zone (Doody, 2013; Pontee, 2013) and a steepening of the coastal profile (Vaselli et al., 2008).

51 Whether SLR will lead to losses or gains in habitat at a given site is highly dependent upon

52 geomorphology, rates of erosion, underlying stratigraphy, and alteration in sedimentation

53 processes at local and regional scales (Emery \& Kuhn, 1980; Young \& Ashford, 2006;

54 Masselink et al., 2020; Schaefer et al., 2020). Studies investigating durable coastlines with low

55 erosion rates have suggested that SLR may cause substantial rocky intertidal habitat loss.

56 Estimates of habitat loss range from $10-27 \%$ and $26-50 \%$ with $0.30 \mathrm{~m}$ and $1.90 \mathrm{~m}$ of SLR,

57 respectively, in northern Scotland (Jackson \& Mcilvenny, 2011), to 10\% and 57\% with 1.0 and

$582.0 \mathrm{~m}$ of SLR, respectively, in Oregon, USA (Hollenbeck, Olsen \& Haig, 2014). Thorner, 
59 Kumar, and Smith. (2014) found that with $0.3-1.0 \mathrm{~m}$ of SLR on five rocky headlands in New

60 South Wales, Australia, impacts will be variable but will largely result in substantial habitat loss.

61 Most recently, Schaefer et al. (2020) suggest that along $50 \mathrm{~km}$ of rocky shoreline in eastern

62 Australia, SLR will generally reduce habitat availability, though impacts will show high spatial

63 variability, with gently sloped shores that lack the ability to migrate landward experiencing the

64 greatest losses of habitat. Because habitat loss is among the greatest threats to global biodiversity

65 (Brooks et al., 2002; Mantyka-Pringle, Martin \& Rhodes, 2012), it is critical to evaluate the

66 current state of rocky intertidal ecosystems and assess how SLR may affect these important

67 communities in coming years.

68 The unique ecological characteristics of rocky intertidal systems may also make them

69 particularly vulnerable to changes in ecological structure and function as a result of SLR. The

70 rocky intertidal zone is characterized by patterns of ecological zonation that manifest as distinct,

71 and sometimes strict, bands along the tidal elevation gradient. These bands are generated by a

72 variety of spatially variable and density-dependent biological mechanisms, such as competition

73 (Connell, 1961; Menge, 1976), mutualism (Menge, 1995; Bertness \& Leonard, 1997), predation

74 (Paine, 1969, 1974, 1980; Menge, 1976), and differences in physiological tolerances to extremes

75 in environmental conditions (Connell, 1972; Paine, 1974). Regardless of the potential for the

76 concomitant provisioning of suitable space via erosion, SLR will cause an upward shift in this

77 banding as the current intertidal zone is submerged. Further, it is unclear whether the changing

78 intertidal zone will be suitable for colonization by many species, as habitat characteristics, such

79 as slope (Vaselli et al., 2008), substrate type (Thorner, Kumar \& Smith, 2014), and physical

80 environmental conditions, such as wave stress and exposure (Harley et al., 2006) may also 
81 change. Thus, coastal squeeze and the rapid upward shift in intertidal area will likely impact the

82 abundance, distribution, and competitive interactions of rocky intertidal species.

\section{Approaches to quantifying climate change impacts in the rocky}

\section{5 intertidal zone}

Rocky intertidal habitats are among the most extensively studied marine ecosystems, and are well known for their rich and varied history of influential research (Ricketts \& Calvin, 1939; Connell, 1961; Lewis, 1964; Paine, 1966, 1974, 1994; Dayton, 1971; Menge, 1976; Sousa, 1979; Paine \& Levin, 1981; Underwood \& Denley, 1984; Gaines \& Roughgarden, 1985; Roughgarden, Gaines \& Possingham, 1988; Underwood, Chapman \& Connell, 2000, to list a few). Despite much advancement in the field, a combination of factors has constrained field sampling designs (Andrew \& Mapstone, 1987). Many studies have been tradition bound, selecting sampling units a priori rather than empirically evaluating the appropriate grain size for the particular question of interest (Andrew \& Mapstone, 1987; Wiens, 1989; Underwood, 2000; Denny et al., 2004). Logistical challenges, such as difficulty of access and a brief sampling window constrained to periods of emersion, have necessitated labor-intensive in-situ surveys, which are limited in

97 spatial extent (Blakeway et al., 2003). While remote sensing approaches have been used to collect data on larger spatial scales, technological limitations have somewhat restricted the resolution and deployment of these approaches. Such limitations have previously been a barrier to determining how SLR will modify ecological patterns and processes in rocky intertidal

101 communities at ecologically relevant spatial scales (Runting, Wilson \& Rhodes, 2013). 
102 Recently, remote-sensing approaches and geographic information system (GIS) analysis software

103 have been used to provide high-resolution, landscape-scale ecological information in the rocky

104 intertidal zone (Guichard, Bourget \& Agnard, 2000; Blakeway et al., 2003; Bryson et al., 2013;

105 Thorner, Kumar \& Smith, 2013; Gomes et al., 2018; Konar \& Iken, 2018; reviewed by Garza,

106 2019). Importantly, when combined with detailed in-situ information, these approaches now

107 provide researchers the opportunity to investigate ecological dynamics at scales commensurate

108 with the landscape processes affecting these communities (Murfitt et al., 2017; Gomes et al.,

109 2018; Garza, 2019).

110 Here, we investigated the potential ecological impacts of future SLR on rocky intertidal

111 ecosystems, using a multi-scale approach at two marine reserves in San Diego, CA, USA as a

112 case study. Light Detection and Ranging (LiDAR) data were used to estimate current intertidal

113 habitat extent at four study sites and site-level habitat area changes under a range of SLR

114 scenarios. Using high-resolution in-situ imaging, we mapped intertidal habitats and quantified

115 the percent cover of dominant benthic space occupiers and the density of sessile and mobile

116 invertebrates across tidal elevations in $180 \mathrm{~m}^{2}$ plots at each site. We then used a model-based

117 approach to investigate future SLR driven changes in the areal extent of dominant benthic space

118 occupiers, and the numerical abundance of focal rocky intertidal invertebrate taxa. This work

119 takes a critical step toward determining the future impact of SLR on rocky intertidal

120 communities at ecologically relevant scales, and provides a framework for future monitoring and

121 experimental efforts.

123 Methods 


\section{Survey locations and sites}

125 Two rocky intertidal study locations in San Diego County were chosen: the Scripps Coastal

126 Reserve (SCR) and the Cabrillo National Monument (CNM) (Fig. 1). Within these locations, one

127 site was sampled at SCR (SCR 0), and three sites were sampled at CNM (CNM 1-3). These

128 locations are recognized for their ecological and economic importance, and are both designated

129 as marine protected areas (MPAs) under California state legislation. Regular long-term

130 ecological monitoring by the Multi-Agency Rocky Intertidal Network (MARINe) has occurred at

131 one site at SCR since 1997, and at three sites at CNM since 1990 ("Multi-Agency Rocky

132 Intertidal Network (MARINe)"). The SCR site was studied under a permit granted by the Scripps

133 Coastal Reserve Manager (application \#: 33783), and CNM sites were studied under a permit

134 granted by the US Department of the Interior National Park Service, Cabrillo (permit \#: CABR-

135 2016-SCI-0007).

136 As previously described by MARINe, the intertidal habitat at SCR is comprised of a gently

137 sloping boulder-field backed by a large metamorphic dike running south by southwest through

138 the site. The dike provides a distinct upper limit to the intertidal zone, which is immediately

139 adjacent to steep cliffs that rise vertically to an elevation of approximately $75 \mathrm{~m}$. CNM2 and

140 CNM3 are characterized by broad and gently sloping sandstone benches, while CNM1 is

141 comprised of large scattered boulders atop the same sandstone base as found at the other CNM

142 sites. At CNM, the intertidal zone is backed by low cliffs, which rise steeply to approximately 5-

$14310 \mathrm{~m}$ elevation, then more gradually to a higher ridge. Cliff stratigraphy in both locations is

144 comprised of lithified mudstone, siltstone, shale, and sandstone, and these cliffs regularly

145 experience failure and variable rates of net yearly erosion (Emery \& Kuhn, 1980; Benumof et al.,

146 2000; Young \& Ashford, 2006). 


\section{SLR scenarios and intertidal area estimation}

149 In the Fifth Assessment Report, the United Nations Intergovernmental Panel on Climate Change

150 (IPCC) projected a rise in global sea-level of between $0.26 \mathrm{~m}$ and $0.98 \mathrm{~m}$ by 2100 (Church et al.,

151 2013). More recently the National Oceanic and Atmospheric Administration (NOAA) released

152 projections that include SLR extremes of up to $2.5 \mathrm{~m}$ on US coastlines (Sweet et al., 2017). Sea-

153 level rise projections for California generally fall within the range of global projections. Cayan et

154 al. (2008) forecasted SLR on the coast of California of $0.11-0.72 \mathrm{~m}$ by 2070-2099 (Cayan et

155 al., 2008). The National Research Council (NRC) projected $0.42-1.67 \mathrm{~m}$ of SLR by 2100 for the

156 coast of California south of Cape Mendocino (National Research Council, 2012). For this study,

157 SLR scenarios from $0.10-2.0 \mathrm{~m}$ were analyzed in $10.0 \mathrm{~cm}$ increments (twenty scenarios) in

158 order to cover the generally accepted potential range of SLR for the California coast in the next

159 century. By analyzing SLR in increments, we also avoided using projections for specific dates,

160 and thus our analysis is not time specific and is more flexible to the uncertainty of the

161 projections.

162 The total area of the intertidal zone at each site currently, and under each SLR scenario, was

163 estimated from the 2009-2011 California Coastal Conservancy Coastal LiDAR Project: Hydro

164 Flattened Bare Earth Digital Elevation Model ("NOAA Digital Coast: Data Access Viewer"),

165 which is hereafter referred to as the site-level DEM or SDEM. WGS1984 and MLLW were

166 selected as horizontal and vertical datums to allow later embedding of orthophotomosaics and

167 direct referencing to common tidal datums. Tidal datums from NOAA tide stations nearest our

168 survey sites were selected as the initial vertical boundaries of each site (S1 Table, Fig. 1). Mean

169 Lower Low Water (MLLW, $0 \mathrm{~m}$ ) was used as the lower boundary of the intertidal because it is a 
170 commonly used datum and the penetration limitations of LiDAR do not allow accurate data

171 below MLLW. Highest astronomical tide (HAT) was chosen as the upper boundary of the

172 intertidal zone, to encompass the zone that is only covered during the highest high tides and the

173 spray zone. Straight lines running perpendicular to the elevation contours through the northern

174 and southern most long-term monitoring plots at each site were established as fixed upcoast and

175 downcoast boundaries (Fig. 1). The DEM Surface Tools Extension for ArcGIS (ESRI 2016.

176 ArcGIS Desktop: Release 10.5 Redlands, CA, USA) was used to provide surface area estimates

177 on a grid by grid basis for the SDEM (Jenness, 2004). The Surface Tools Extension accounts for

178 vertical relief values in area estimates by using adjusted surface area values for each SDEM grid

179 cell rather than strictly planimetric area (Jenness, 2004).

180 As future erosion rates are difficult to estimate, we chose to follow a passive flooding approach.

181 In each SLR scenario at each site, total intertidal area was estimated by adjusting the vertical

182 boundaries to the future intertidal extent (current datums + SLR), then summing surface area of

183 SDEM grid cells within the future intertidal extent. This allowed migration of the realized

184 available habitat upward and shoreward under each SLR scenario, so that predicted SLR was

185 applied to the existing coastal topography of our sites in our modeling (e.g. Vaselli et al., 2008).

186 Thus, we prevented artificial constraint on the upper limit of the intertidal zone during future

187 scenarios. These surface area values were also subset to allow analyses by intertidal zone (e.g.

188 lower, middle, and upper, S1 Table).

190 Large-area imaging of intertidal survey plots and image processing

191 In order to characterize the composition of the biological communities at these sites, we used an

192 imaging approach referred to as large-area imaging, which produces spatially accurate, detailed 
193 maps of the benthos from digital imagery collected in field plots (Murfitt et al. 2017, Edwards et

194 al. 2017). The general large-area imaging workflow involves the use of commercially available

195 Structure-from-Motion photogrammetry (SfM) software (Agisoft PhotoScan Professional V.1.3

196 software (Agisoft LLC 2014, St. Petersburg, Russia)). This software allows creation of

197 composite 3-dimensional reconstructions, also known as 3D models, from raw imagery. We then

198 generate plot-scale Digital Elevation Models (PDEM) and orthorectified 2-dimensional top-

199 down views, or orthophotomosaics, of the 3D models (Fig. 2). These 2D models are then scaled

200 and uploaded into ArcGIS for ecological analysis and extraction of landscape scale metrics.

201 At each site imaging plots were positioned to span the maximal distance across the intertidal

202 zone, while also overlapping a subset of the long-term study sites. To establish plot locations, ten

203 random coordinates were first generated in ArcGIS within the upper zone of the SDEM at each

204 site. Coordinates were then ground-truthed to ensure they occurred on natural substrate within

205 representative upper-intertidal habitat. One coordinate was then randomly selected from the

206 coordinates meeting these criteria as the upper, up-coast corner for the plot at each site.

207 Rectangular $6.0 \mathrm{~m} \times 30.0 \mathrm{~m}$ plots were then established running perpendicular to the shoreline

208 along the elevation gradient. Plots of this size were deemed sufficient for accomplishing project

209 goals while also balancing image and data processing capabilities.

210 Imagery was collected at all sites between December 2016 and January 2017, concurrent with

211 the season's lowest tides and with existing long-term monitoring surveys. A GoPro Hero 5

212 camera (GoPro Inc., San Mateo, CA) was mounted to a frame on a handheld transect line and

213 passed between two surveyors across the plot, with adjacent passes separated by $0.5 \mathrm{~m}$. Images

214 were collected every 0.5 seconds using a linear field of view setting with an equivalent focal

215 length of 24-49 $\mathrm{mm}$. The camera was held approximately $1.0 \mathrm{~m}$ above the substrate to maximize 
216 overlap of images while also ensuring sufficient image resolution for benthic community

217 identifications. Ten scale bars of known length $(0.5 \mathrm{~m})$ were deployed throughout the plot as $\mathrm{x}$,

$218 \mathrm{y}$, z spatial references, and ground control point (GCP) coordinates were collected at the upcoast

219 end of each scale bar. Images were collected over a $9.0 \mathrm{~m}$ x $33.0 \mathrm{~m}$ area to ensure that the target

220 plot was imaged with sufficient coverage ( $1.5 \mathrm{~m}$ buffer around perimeter) to avoid areas of

221 missing data within the study plot.

222 The details of 3D model and orthophotomosaic creation have been described in detail elsewhere

223 (Burns et al., 2015; Naughton et al., 2015; Murfitt et al., 2017). Briefly, Agisoft was used to first

224 align imagery, estimate camera positions and scene geometry, and produce a sparse cloud of

225 points extracted from the imagery. These sparse clouds were then optimized to correct model

226 geometry and minimize alignment error and assigned a coordinate system and scale using GCP

227 coordinates and lengths from the scale bars within each plot. Textured dense point clouds were

228 then produced and subsequently meshed to provide PDEMs (1.0 cm nominal post spacing).

229 Finally, top down orthophotomosaics $(0.3-0.4 \mathrm{~mm} /$ pixel resolution) were produced to allow

230 visual identification and quantification of benthic organisms (Fig. 2). This resolution allowed

231 identification of organisms of sizes greater than or equal to approximately $1.0 \mathrm{~cm}$ in diameter,

232 though taxonomic resolution varied depending on morphology. Orthophotomosaics and PDEMs

233 were exported from Agisoft in a raster format, and uploaded into ArcGIS for subsequent data

234 extraction.

235

236 Biological data extraction

237 Percent cover estimates: To characterize current percent cover of dominant benthic space

238 occupiers across tidal elevations at each site, stratified random point sampling was conducted 
239 within each orthophotomosaic using ArcGIS. First, a grid of 9600 equal sized rectangular cells

$240(12.5 \mathrm{~cm} \times 15.0 \mathrm{~cm})$ was generated across each plot. Then, one point was randomly placed

241 within each grid cell, and these points were manually identified to the highest taxonomic

242 resolution possible (see S2 Table for species identifications). Conspicuous seaweeds and

243 invertebrates were identifiable to the species level, but morphologically indistinct (e.g. non-

244 coralline crust algae, foliose red algae) and smaller taxa, or taxa that grow in mixed communities

245 (e.g. articulated coralline algae, turf algae, crustose coralline algae), were grouped into functional

246 categories. Estimates of SLR driven changes were only made for those taxa that 1) were directly

247 attached to the benthos anywhere they were visible, and 2) were easily distinguished from other

248 taxa in our orthophotomosaics. In situations where epiphytes were present (e.g. fleshy algae

249 growing on mussels) we identified the taxa attached to the benthos upon which the epiphytes

250 were growing.

251 Tidal elevation for each stratified random point was extracted from the PDEMs, allowing the

252 calculation of the percent cover of each taxon in $10.0 \mathrm{~cm}$ tidal elevation bins (hereafter referred

253 to simply as bins) across each plot. The percent cover of each taxon in each bin within each plot

254 was calculated as the percent of points falling on that taxon out of the total number of points

255 falling in the respective bin. These percent cover values were later used to estimate areal extent

256 of dominant benthic space occupiers in each SLR scenario.

257 Invertebrate density estimates: To estimate the current density $\left(\# / \mathrm{m}^{2}\right)$ of focal invertebrate taxa

258 across tidal elevations, systematic counts of invertebrates larger than $1.0 \mathrm{~cm}$ in diameter were

259 conducted within each plot. This included both motile and sessile species (S2 table). Species

260 counts were conducted at a consistent scale (1:4), allowing identification near the limit of

261 orthophotomosaic resolution. Only invertebrate taxa that could be clearly identified at this scale 
262 were counted. Because this approach is image based, it is likely that taxa occupying cryptic

263 habitat or hidden by layering were underestimated in our counts. The density of each taxon in

264 each bin in each plot was calculated as the total number of individuals observed divided by the

265 total area within each elevational bin as calculated from the PDEMs. These data were later used

266 to provide estimates of numerical abundance of invertebrate species under each SLR scenario.

268 SLR impacts to areal extent and invertebrate abundances

269 In order to assess how changes in habitat area as a result of SLR may influence the rocky

270 intertidal community at our sites, the total areal extent $\left(\mathrm{m}^{2}\right)$ of dominant benthic space occupiers

271 and the abundance of focal invertebrate taxa (\#) was estimated for each site under each SLR

272 scenario. These estimates were produced by extrapolating the estimates of percent cover and

273 density from the orthophotomosaics and PDEMs to the more spatially expansive SDEMs. The

274 total areal extent $\left(\mathrm{m}^{2}\right)$ of each dominant benthic space occupier in each SLR scenario at each site

275 was calculated by multiplying the percent cover of each species in each bin by the total area in

276 the respective bin as calculated from the SDEM, and then summing across bins. This metric

277 provided an assessment of how SLR will influence absolute areal extent of each taxon and

278 allowed comparison of relative changes in area. The abundance for each focal invertebrate taxon

279 in each SLR scenario at each site was calculated by multiplying the current density of each taxon

280 in each bin by the total area in the respective bin as calculated from the SDEM, and then

281 summing across bins.

282

283 Results 


\section{Change in intertidal habitat area and zonation with SLR}

285 We estimated habitat area within current and future intertidal elevation ranges at our study sites

286 and found that SLR will substantially reduce total intertidal habitat area $\left(\mathrm{m}^{2}\right)$ (Fig. 3). Following

287 a SLR trajectory consistent with the observed trend in San Diego, CA, (approximately $20.0 \mathrm{~cm}$

288 by 2100$)$, we estimate that total intertidal habitat area loss will be on average $29.88 \%( \pm 3.78$,

289 SE) across these study sites. Under the IPCC upper-end global projection of $1.0 \mathrm{~m}$ by 2100

290 (Church et al., 2013), this value will reach 77.72\% ( \pm 4.65$)$. Under the NRC upper-end

291 projection for California (National Research Council, 2012) of $1.7 \mathrm{~m}$, this value will rise to

$29285.32 \%( \pm 2.33)$. Habitat loss will be greatest for the lower and middle intertidal zones, which

293 currently occupy a broad and gently sloping intertidal shelf that will rapidly become subtidal as

294 sea-levels rise (Fig. 3). Under scenarios greater than $0.2 \mathrm{~m}$ the lower intertidal zone will nearly

295 always experience the greatest proportional habitat area loss, followed by the middle, then upper

296 zones (Fig. 3). As a result, we expect that the proportional contribution of each zone to total

297 intertidal area will shift, with the contribution of the lower intertidal zone diminishing, and that

298 of the middle and upper zones increasing (Fig. 3, S1 Fig.).

299

300 Change in areal extent of dominant benthic space occupiers with

301 SLR

302 With little exception, we found that the SLR scenarios examined here will result in reductions in

303 areal extent $\left(\mathrm{m}^{2}\right)$ of dominant benthic space occupiers. Importantly, our data suggest that species

304 will experience changes in areal extent of different magnitudes, resulting in changes in

305 community structure as the relative abundance of species shifts (Fig. 4). The most pronounced 
306 changes will likely occur in the first $0.5 \mathrm{~m}$ of SLR for all species. At $0.5 \mathrm{~m}$ of SLR, we estimate

307 a mean decrease in total areal extent across all species and study sites of $56.95 \%( \pm 2.40)$.

308 Changes in areal extent will be most pronounced for those taxa that primarily occupy lower and

309 middle intertidal habitats, such as articulated coralline algae, some brown algae, red foliose

310 algae, turf algae, and surfgrass (see S2 Table for species identifications and classifications). For

311 example, we estimate that the total areal extent of articulated coralline algae at our study sites

312 will decrease by an average of $83.74 \%$ ( $\pm 4.72 \mathrm{SE}$; range $70.10-91.77)$ under the IPCC upper-

313 end projection. Areal extent is expected to change less dramatically for taxa occupying primarily

314 upper intertidal habitat, such as mussels and barnacles. For example, we estimate that the total

315 areal extent of barnacles (Balanus/Chthamalus spp.) will decrease by an average of $52.99 \%( \pm$

316 12.01; range 20.38 - 77.84) across our study sites under the IPCC upper-end projection.

318 Change in invertebrate abundance with SLR

319 Our results suggest that there will be nearly ubiquitous declines in overall numerical abundance

320 of sessile and mobile invertebrates at our study sites with future SLR (Fig. 5). Lower and middle

321 intertidal taxa will likely exhibit greater population declines than upper intertidal taxa, and the

322 largest declines will be observed in the first 0.5 - 1.0 meter of SLR. For example, our results

323 suggest that the abundance of green solitary anemone (Anthopleura sola/xanthogrammica) will

324 decrease by an average of $64.37 \%( \pm 8.66)$ and $76.20 \%( \pm 15.60)$ across our study sites at 0.5

325 and $1.0 \mathrm{~m}$ of SLR, respectively. In contrast, we estimate smaller declines in the abundance of

326 upper intertidal periwinkles (Littorina spp.) with $26.22 \%( \pm 14.9)$ and $51.19 \%( \pm 0.17)$ and upper

327 intertidal gooseneck barnacles (Pollicipes polymerus (Sowerby, 1883)) with 29.10\% $( \pm 5.60)$ and

$32847.14 \%( \pm 7.54)$ across study sites at 0.5 and $1.0 \mathrm{~m}$ of SLR, respectively. Overall our results 
329 suggest mean decreases in total abundance of all invertebrates at our study sites of $55.82 \%$ ( \pm

$3304.25)$ and $66.92 \%( \pm 4.09)$ under the IPCC and NRC projections, respectively. These results

331 however, do not take into account the possibility of these species becoming increasingly subtidal.

332

\section{Discussion}

334 Here we used a multi-scale approach to investigate how predicted SLR over the next century

335 may affect rocky intertidal communities at four sites in San Diego, CA, USA. Our results suggest

336 that SLR will significantly reduce total rocky intertidal habitat area at our study sites. These

337 changes will neither occur uniformly across time nor space, but rather will be most pronounced

338 during the first meter of SLR and within the lower and middle intertidal zones. As seas rise, the

339 broad intertidal zones at our study locations will be quickly submerged, resulting in first rapid,

340 then more gradual, loss of intertidal habitat area. As this bench habitat is lost, the intertidal zone

341 will likely be squeezed into the remaining habitat, most of which is more vertical in nature.

342 While much remains unknown regarding the realized effects of SLR along the coast of southern

343 California, our results provide an empirically based framework to investigate the potential

344 magnitude of changes to intertidal communities as a result of SLR.

345 While our results apply most directly to our specific study locations, rocky intertidal shores

346 around the globe may be susceptible to coastal squeeze, as many are often composed of erosion

347 resistant benches backed by steep coastal cliffs (Emery \& Kuhn, 1982; Graham, Dayton \&

348 Erlandson, 2003). The ability of SLR driven erosion to create new habitat will depend both on

349 the rate of erosion, which must keep up with inundation, and the availability of suitable habitat,

350 which is dependent upon the underlying stratigraphy of the eroding shoreline (Masselink et al.,

351 2020). In the locations considered here, which are comprised of a mix of loosely compacted 
352 sedimentary materials interspersed with more durable sandstone (Young 2010, Kuhn 1980), it is

353 unclear if erosion will be able to open up new habitat. Further, habitat loss from sedimentation

354 may also occur as a result of changes in erosional processes at adjacent locations. Ultimately, the

355 degree to which our results are applicable to other areas will depend strongly on complex, and

356 likely interacting, local and regional scale processes which remain poorly understood (Nicholls

357 \& Cazenave, 2010; Masselink et al., 2020).

358 Our findings are generally consistent with those of other studies that have attempted to forecast

359 the effects of SLR on future intertidal area and coastal profile of rocky shores. For example,

360 Jackson and Mcilvenny (2011), Thorner, Kumar and Smith (2013), Hollenbeck, Olsen and Haig

361 (2014), and Schaefer et al. (2020) estimated that SLR will significantly reduce intertidal habitat

362 area. In addition, Vaselli et al. (2008) and Jackson and Mcilvenny (2011) suggest that as seas

363 rise, the intertidal zone will generally steepen. Habitat area is among the most significant factors

364 limiting the growth and abundance of rocky intertidal species (Dayton, 1971). Thus, the changes

365 in habitat area that are likely to occur due to SLR will also likely affect intertidal community

366 structure. Our results suggest generally negative impacts to both the total areal extent of

367 dominant benthic space occupiers and the numerical abundance of sessile and mobile

368 invertebrates at our survey sites, even under modest SLR scenarios well within the range

369 projected for the next century. With reduced space for colonization, and assuming densities

370 remain similar to what they are today, substantial declines in the populations of intertidal

371 organisms are expected.

372 However, it is also possible that abundances will initially remain fairly constant, leading to

373 increased densities of both sessile and mobile species. As habitat area is compressed, the biotic

374 interactions known to drive community structure such as competition and predation are likely to 
375 change (Dayton, 1971). Additionally, interactions that were otherwise rare or non-existent due to

376 the spatial separation between species may become intensified or be created (Jackson \&

377 Mcilvenny, 2011). Further, because rocky intertidal organisms exhibit distinct distributions

378 across tidal elevations, and a range of life history strategies (Connell, 1972; Paine, 1974), the

379 impact of SLR will likely be non-uniform and unpredictable across the rocky intertidal

380 community, both taxonomically and through time. Such changes in these biotic interactions will

381 inevitably play an important role in ultimately determining how SLR impacts this ecosystem.

382 The expanded use of in-situ image-based approaches such as that used here promises to increase

383 the scope, scale, and extent over which scientists can study habitats such as the rocky intertidal.

384 While this approach dramatically increases spatial scale relative to traditional field survey

385 efforts, there remain limitations inherent in the use of imagery for describing intertidal

386 communities. Any imaging approach in the intertidal will be largely restricted to assessing

387 mostly horizontal and outer surface layer organisms, thus missing cryptic taxa and understory

388 species. Further, taxonomic resolution is limited based upon the quality and resolution of the

389 imagery, and the choice of imaging platform should realistically be made with careful

390 consideration of the question of interest (Konar \& Iken, 2018). However, when combined with

391 traditional in situ sampling and collection of voucher specimens to identify cryptic taxa, the

392 approach outlined here has the capacity to increase the scope of data that can be collected. In

393 particular, the ability to derive spatially explicit biological and landscape metrics will allow more

394 accurate predictions of how intertidal communities may change over time (Guichard, Bourget \&

395 Agnard, 2000; Blakeway et al., 2003; Bryson et al., 2013; Murfitt et al., 2017; Konar \& Iken,

396 2018; Garza, 2019). 
398 Conclusions

399 Here we provide a framework for evaluating the potential effects of sea level rise on one of the

400 most important marine ecosystems at ecologically relevant spatial scales. At our focal study sites

401 in San Diego, CA, we found compelling evidence that SLR will likely substantially reduce total

402 area of intertidal habitat and thus the areal extent and numerical abundance of species occupying

403 this habitat. However, to more broadly evaluate how SLR is likely to affect the rocky intertidal

404 zone, even larger scale approaches across more study sites and regions are needed. Future studies

405 should consider how differences in the underlying geomorphological features of study sites such

406 as slope, habitat complexity, and erosion rates could alter SLR impacts. Future studies should

407 also incorporate information on physical parameters known to influence spatial heterogeneity in

408 rocky intertidal community organization that will likely evolve under global climate change,

409 such temperature (Helmuth et al., 2002), ocean chemistry (Kroeker, Micheli \& Gambi, 2013;

410 Kroeker et al., 2016), and wave intensity (Cayan et al., 2008).

411 The rocky intertidal zone is one of the most accessible of marine environments, and is of

412 immense recreational, commercial, and educational value to coastal societies worldwide. These

413 systems are likely to be substantially modified by large-magnitude global SLR on an accelerated

414 and uncertain timeline within the next century. Our results highlight the need for ecosystem-scale

415 evaluations in order to quantify and visualize the global change impacts that will modify the

416 structure and function of this unique ecosystem. Similar approaches are needed more broadly for

417 global coastlines in order to understand how to manage and mitigate impending global change

418 impacts (Runting, Wilson \& Rhodes, 2013; Murfitt et al., 2017). 


\section{Acknowledgements}

421 The authors would like to acknowledge C. Amir, L. Bonito, D. Chargualaf, and A. Martinez for

422 their assistance collecting field data, J. Jones and K. Lombardo for assistance with acquiring

423 permits and accessing Cabrillo National Monument sites, I. Kaye for providing permits to access

424 the Scripps Coastal Reserve, J. Jenness for advice on analyzing DEM data in GIS and on the use

425 of the DEM Surface Analyst extension for ArcGIS, S.A. Sandin for modeling the use of large-

426 area imaging for studying spatial ecology, E. Parnell for his natural history guidance, V. Petrovic

427 for his assistance with 3D model visualization, and N. Pederson for assistance with image

428 processing. 
430 References

431 Andrew N, Mapstone B. 1987. Sampling and the description of spatial pattern in marine ecology.

432 Oceanography and Marine Biology 25:26-69.

433 Benumof BT, Storlazzi CD, Seymour RJ, Griggs GB. 2000. The Relationship between Incident

434 Wave Energy and Seacliff Erosion Rates: San Diego County, California. Journal of Coastal

$435 \quad$ Research 16:1162-1178.

436 Bertness MD, Leonard GH. 1997. The role of positive interactions in communities: Lessons from

437 intertidal habitats. Ecology 78:1976-1989. DOI: 10.1890/0012-

$438 \quad 9658(1997) 078[1976:$ TROPII]2.0.CO;2.

439

440

441

442

443

444

445

446

447

448

449

450

Blakeway D, Robles C, Fuentes D, Qiu H-L. 2003. Spatially Extensive, High Resolution Images of Rocky Shore Communities. Handbook of Scaling Methods in Aquatic Ecology:109-123. DOI: $10.1201 / 9780203489550 . \operatorname{ch} 7$.

Brooks TM, Mittermeier RA, Mittermeier CG, Da Fonseca GAB, Rylands AB, Konstant WR, Flick P, Pilgrim J, Oldfield S, Magin G, Hilton-Taylor C. 2002. Habitat Loss and Extinction in the Hotspots of Biodiversity. Conservation Biology 16:909-923. DOI: 10.1046/j.15231739.2002.00530.x.

Bryson M, Johnson-Roberson M, Murphy RJ, Bongiorno D. 2013. Kite Aerial Photography for Low-Cost, Ultra-high Spatial Resolution Multi-Spectral Mapping of Intertidal Landscapes. PLoS ONE 8(9): e73550. DOI: 10.1371/journal.pone.0073550.

Burns JHR, Delparte D, Gates RD, Takabayashi M. 2015. Integrating structure-from-motion photogrammetry with geospatial software as a novel technique for quantifying 3D 

ecological characteristics of coral reefs. PeerJ 3:e1077. DOI: 10.7717/peerj.1077.

452 Cayan DR, Bromirski PD, Hayhoe K, Tyree M, Dettinger MD, Flick RE. 2008. Climate change 453 projections of sea level extremes along the California coast. Climatic Change 87:s57-s73. 454 DOI: $10.1007 / \mathrm{s} 10584-007-9376-7$.

455 Cazenave A, Dieng H, Meyssignac B, Schuckmann K Von, Decharme B, Berthier E. 2014. The 456 rate of sea-level rise. Nature Climate Change 4:358-361. DOI: 10.1038/NCLIMATE2159.

457 Chen X, Zhang X, Church JA, Watson CS, King MA, Monselesan D, Legresy B, Harig C. 2017. 458 The increasing rate of global mean sea-level rise during 1993 - 2014. Nature Climate Change 7:492-495. DOI: 10.1038/NCLIMATE3325.

Church JA, Clark PU, Cazenave A, Gregory JM, Jevrejeva S, Levermann A, Merrifield MA, 461 Milne GA, Nerem R., Nunn PD, Payne AJ, Pfeffer WT, Stammer D, Unnikrishnan AS. 462 2013. Sea level change. Climate Change 2013: The Physical Science Basis. Contribution of

465 Church JA, White NJ. 2006. A 20th century acceleration in global sea-level rise. Geophysical 466 Research Letters 33:94-97. DOI: 10.1029/2005GL024826.

467 Connell JH. 1961. The influence of interspecific competition and other factors on the distribution 468 of the barnacle Chthalamus stellatus. Ecology 42:710-723.

469 Connell JH. 1972. Interactions on Marine Rocky Intertidal Shores. Annual Review of Ecology 470 and Systematics 3:169-192. DOI: doi:10.1146/annurev.es.03.110172.001125.

471 Dayton PK. 1971. Competition, Disturbance, and Community Organization: The Provision and 472 Subsequent Utilization of Space in a Rocky Intertidal Community. Ecological Monographs 
Denny MW, Helmuth B, Leonard GH, Harley CDG, Hunt LJH, Nelson EK. 2004. Quantifying Scale in Ecology : Lessons from a Wave-Swept Shore. Ecological Monographs 74:513532.

Denny M, Paine R. 1998. Celestial mechanics, sea level changes, and intertidal ecology. Biological Bulletin 194:108-115. DOI: Doi 10.2307/1543040.

Doody JP. 2013. Coastal squeeze and managed realignment in southeast England, does it tell us anything about the future? Ocean and Coastal Management 79:34-41. DOI: 10.1016/j.ocecoaman.2012.05.008.

Edwards CB, Eynaud Y, Williams GJ, Pedersen NE, Zgliczynski BJ, Gleason ACR, Smith JE, patterns of corals at a remote reef. Coral Reefs 36:1-15. DOI: 10.1007/s00338-017-1624-3.

Emery KO, Kuhn GG. 1980. Erosion of Rock Shores at La Jolla, California. Marine Geology 37:197-208.

Emery KO, Kuhn GG. 1982. Sea cliffs: their processes, profiles, and classification. Geological Society of America Bulletin 93:644-654. DOI: 10.1130/00167606(1982)93<644:SCTPPA>2.0.CO;2.

Gaines S, Roughgarden J. 1985. Larval Settlement Rate : A Leading Determinant of Structure in an Ecological Community of the Marine Intertidal Zone. Proceedings of the National Academy of Sciences 82:3707-3711. 
496 Gomes I, Peteiro L, Bueno-Pardo J, Albuquerque R, Pérez-Jorge S, Oliveira ER, Alves FL,

497 Queiroga H. 2018. What's a picture really worth? On the use of drone aerial imagery to 498 estimate intertidal rocky shore mussel demographic parameters. Estuarine, Coastal and 499 Shelf Science 213:185-198. DOI: 10.1016/j.ecss.2018.08.020.

500 Guichard F, Bourget E, Agnard JP. 2000. High-resolution remote sensing of intertidal 501 ecosystems: A low-cost technique to link scale-dependent patterns and processes. 502 Limnology and Oceanography 45:328-338. DOI: 10.4319/1o.2000.45.2.0328.

503 Harley CDG, Hughes RA, Hultgren KM, Miner BG, Sorte CJB, Thornber CS, Rodriguez LF, 504 Tomanek L, Williams SL. 2006. The impacts of climate change in coastal marine systems. 505 Ecology Letters 9:228-241. DOI: 10.1111/j.1461-0248.2005.00871.x.

506 Helmuth B, Harley CDG, Halpin PM, O’Donnell M, Hofmann GE, Blanchette CA. 2002.

507 Climate change and latitudinal Patterns of Intertidal thermal stress. Science 298:1015-1018. $508 \quad$ DOI: $10.1126 /$ science. 1076814.

Helmuth B, Mieszkowska N, Moore P, Hawkins SJ. 2006. Living on the Edge of Two Changing

510 Worlds: Forecasting the Responses of Rocky Intertidal Ecosystems to Climate Change.

511 Annual Review of Ecology, Evolution, and Systematics 37:373-404. DOI:

$512 \quad 10.2307 / 30033837$.

513 Hoegh-Guldberg O, Bruno JF. 2010. The Impact of Climate Change on the World's Marine 514 Ecosystems. Science 328:1523-1529. DOI: 10.1126/science.1189930.

515 Hollenbeck JP, Olsen MJ, Haig SM. 2014. Using terrestrial laser scanning to support ecological 516 research in the rocky intertidal zone. Journal of Coastal Conservation 18:701-714. DOI: 
518 Jackson AC, Mcilvenny J. 2011. Coastal squeeze on rocky shores in northern Scotland and some

519 possible ecological impacts. Journal of Experimental Marine Biology and Ecology

520 400:314-321. DOI: 10.1016/j.jembe.2011.02.012.

521 Jenness JS. 2004. Calculating landscape surface area from digital elevation models. Wildlife

$522 \quad$ Society Bulletin 32:829-839.

523 Konar B, Iken K. 2018. The use of unmanned aerial vehicle imagery in intertidal monitoring.

524 Deep-Sea Research Part II 147:79-86. DOI: 10.1016/j.dsr2.2017.04.010.

525 Kroeker KJ, Micheli F, Gambi MC. 2013. Ocean acidification causes ecosystem shifts via

526 altered competitive interactions. Nature Climate Change 3:156-159. DOI:

$527 \quad 10.1038 /$ nclimate1680.

528 Kroeker KJ, Sanford E, Rose JM, Blanchette CA, Chan F, Chavez FP, Gaylord B, Helmuth B,

529 Hill TM, Hofmann GE, Mcmanus MA, Menge BA, Nielsen KJ, Raimondi PT, Russell AD,

$530 \quad$ Washburn L. 2016. Interacting environmental mosaics drive geographic variation in mussel

531 performance and predation vulnerability. Ecology Letters:771-779. DOI:

$532 \quad$ 10.1111/ele.12613.

533 Lewis JR. 1964. The Ecology of Rocky Shores. London, England: The English Universities Press $534 \quad$ LTD.

535 Mantyka-Pringle CS, Martin TG, Rhodes JR. 2012. Interactions between climate and habitat loss 536 effects on biodiversity: A systematic review and meta-analysis. Global Change Biology 537 18:1239-1252. DOI: 10.1111/j.1365-2486.2011.02593.x.

538 Masselink G, Russell P, Rennie A, Brooks S, Spencer T. 2020. Impacts of climate change on 
coastal geomorphology and coastal erosion relevant to the coastal and marine environment around the UK. MCCIP Science Review 2020:158-189. DOI: 10.14465/2020.arc08.cgm.

541 Mcleod E, Poulter B, Hinkel J, Reyes E, Salm R. 2010. Sea-level rise impact models and 542 environmental conservation: A review of models and their applications. Ocean \& Coastal 543 Management 53:507-517. DOI: 10.1016/j.ocecoaman.2010.06.009.

544 Menge BA. 1976. Organization of the New England Rocky Intertidal Community: Role of

545 Predation, Competition, and Environmental Heterogeneity. Ecological Monographs 46:355-393. DOI: $10.2307 / 1942563$.

Menge BA. 1995. Indirect Effects in Marine Rocky Intertidal Interaction Webs : Patterns and Importance. Ecological Monographs 65:21-74.

Murfitt SL, Allan BM, Bellgrove A, Rattray A, Young MA, Ierodiaconou D. 2017. Applications of unmanned aerial vehicles in intertidal reef monitoring. Scientific Reports 7:1-11. DOI: 10.1038/s41598-017-10818-9.

National Research Council. 2012. Sea-Level Rise for the Coasts of California, Oregon, and Washington: Washington, DC: The National Academies Press. DOI: 10.17226/13389.

Naughton P, Edwards C, Petrovic V, Kastner R, Kuester F, Sandin S. 2015. Scaling the Annotation of Subtidal Marine Habitats. WUWnet. DOI: 10.1145/2831296.2831342.

Nicholls RJ, Cazenave A. 2010. Sea-Level Rise and Its Impact on Coastal Zones. Science 328:1517-1520. DOI: 10.1126/science.1185782.

NOAA Digital Coast: Data Access Viewer. Available at https://coast.noaa.gov/dataviewer/ 
561 Paine RT. 1966. Food Web Complexity and Species Diversity. The American Naturalist 100:6556275.

563 Paine RT. 1969. A Note on Trophic Complexity and Community Stability. The American $564 \quad$ Naturalist 103:91-93. DOI: 10.1086/282586.

565 Paine RT. 1974. Intertidal Community Structure. Experimental Studies on the Relationship 566 between a Dominant Competitor and Its Principal Predator. Oecologia 15:93-120.

567 Paine RT. 1980. Food Webs: Linkage, Interaction Strength and Community Infrastructure. $568 \quad$ Journal of Animal Ecology 49:666-685.

569 Paine RT. 1994. Marine Rocky Shores and Community Ecology: An Experimentalist's $570 \quad$ Perspective. Excellence in Ecology:175. DOI: 10.1002/iroh.19960810212.

571 Pontee N. 2013. Defining coastal squeeze: A discussion. Ocean and Coastal Management 84:1572 4. DOI: $10.1016 /$ j.ocecoaman.2013.07.010.

573 Rahmstorf S. 2010. A new view on sea level rise. Nature Reports Climate Change 4:0-1. DOI: $574 \quad 10.1029 / 2010 G L 042947$.

575 Ricketts EF, Calvin J. 1939. Between Pacific Tides. Stanford, California: Stanford University $576 \quad$ Press.

577 Roughgarden J, Gaines S, Possingham H. 1988. Recruitment dynamics in complex life cycles. 578 Science 241:1460-1466. DOI: 10.1126/science.11538249.

579 Runting RK, Wilson KA, Rhodes JR. 2013. Does more mean less? The value of information for 580 conservation planning under sea level rise. Global Change Biology 19:352-363. DOI:

$581 \quad 10.1111 / \mathrm{gcb} .12064$. 
582 Schaefer N, Mayer-Pinto M, Griffin KJ, Johnston EL, Glamore W, Dafforn KA. 2020. Predicting

583 the impact of sea-level rise on intertidal rocky shores with remote sensing. Journal of

584 Environmental Management 261. DOI: https://doi.org/10.1016/j.jenvman.2020.110203.

585 Sousa WP. 1979. Disturbance in Marine Intertidal Boulder Fields : The Nonequilibrium

586 Maintenance of Species Diversity. Ecology 60:1225-1239.

587 Sweet W V., Kopp RE, Weaver CP, Obeysekera J, Horton RM, Thieler ER, Zervas C. 2017.

588 Global and Regional Sea Level Rise Scenarios for the United States. Silver Spring, 589 Maryland, USA.

590 Thompson R, Crowe T, Hawkins S. 2002. Rocky intertidal communities: Past environmental 591 changes, present status and predictions for the next 25 years. Environmental Conservation 592 29:168-191. DOI: 10.1017/S0376892902000115.

593 Thorner J, Kumar L, Smith SDA. 2013. Fine-Scale Three-Dimensional Habitat Mapping as a 594 Biodiversity Conservation Tool for Intertidal Rocky Reefs. Journal of Coastal Research 595 29:1184-1190. DOI: 10.2112/JCOASTRES-D-12-00142.1.

596 Thorner J, Kumar L, Smith SDA. 2014. Impacts of climate-change-driven sea level rise on 597 intertidal rocky reef habitats will be variable and site specific. PLoS ONE 9:1-7. DOI: $598 \quad$ 10.1371/journal.pone.0086130.

599 Underwood AJ. 2000. Experimental ecology of rocky intertidal habitats: what are we learing? $600 \quad$ Journal of Experimental Marine Biology and Ecology 25:51-76.

601 Underwood AJ, Denley EJ. 1984. Paradigms, explanations and generalizations in models for the 602 structure of intertidal communities on rocky shore. In: Strong DR, Simberloff D, Abele LG, 603 Thistle AB eds. Ecological Communities: The Conceptual Issues and the Evidence. 
604 Princeton, New Jersey: Princeton University Press, 99-116.

605 Vaselli S, Bertocci I, Maggi E, Benedetti-Cecchi L. 2008. Assessing the consequences of sea

606 level rise: Effects of changes in the slope of the substratum on sessile assemblages of rocky

607 seashores. Marine Ecology Progress Series 368:9-22. DOI: 10.3354/meps07625.

608 Wiens JA. 1989. Spatial scaling in ecology. Functional Ecology 3:385-397.

609 Young AP, Ashford SA. 2006. Application of Airborne LIDAR for Seacliff Volumetric Change

610 and Beach-Sediment Budget Contributions. Journal of Coastal Research 22:307-318. DOI:

$611 \quad 10.2112 / 05-0548.1$ 


\section{Figure 1}

Study site overview.

Location of large-area imaging plots (orange rectangles) in San Diego, CA, USA. Sites were selected to fall within long-term monitoring areas (upcoast and downcoast boundaries, black lines), and were bounded by Highest Astronomical Tide (HAT, light red contour) and Mean Lower Low Water (MLLW, dark red contour). 


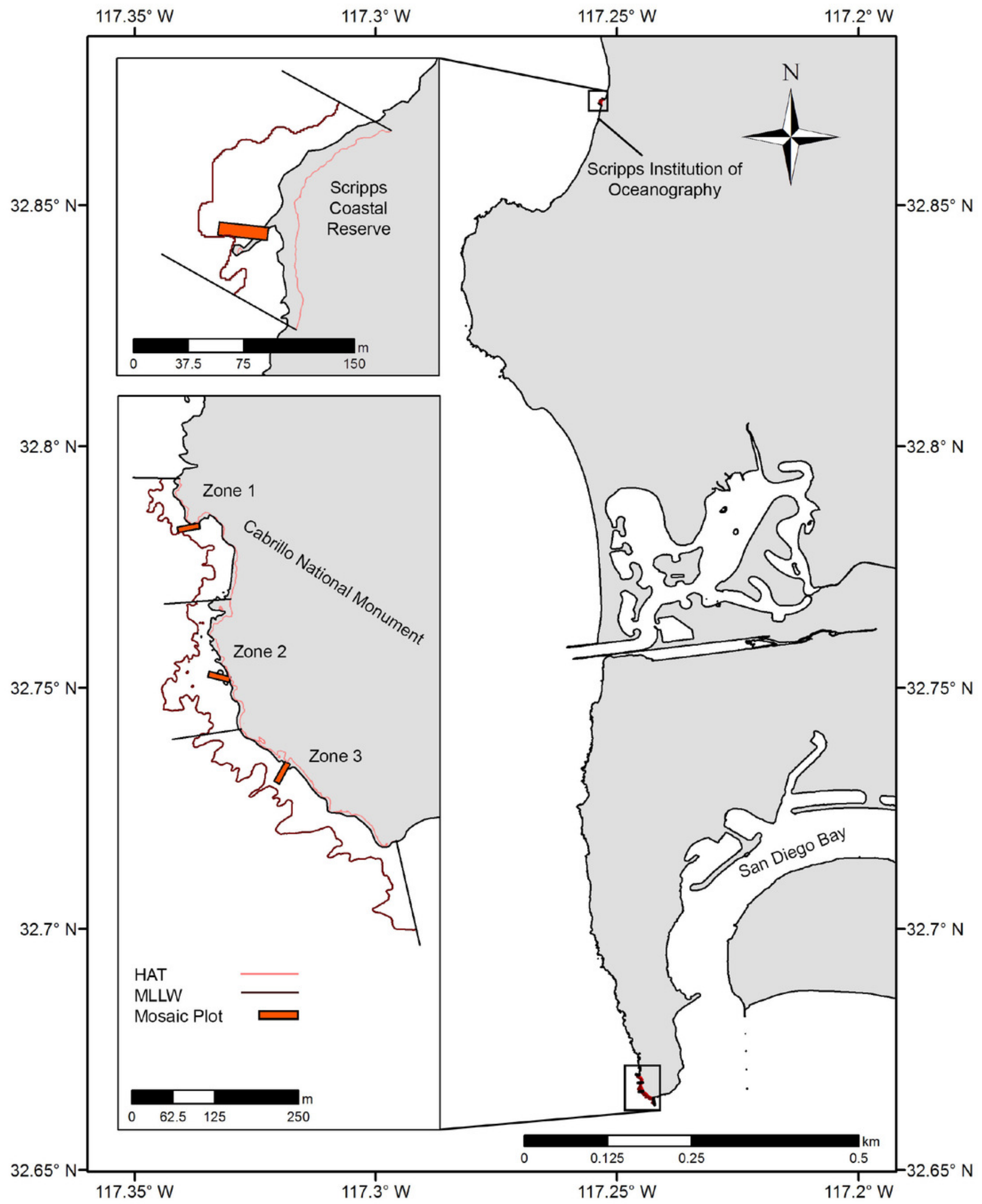


Figure 2

Survey plot orthophotomosaic and Digital Elevation Model (DEM)

(A) Example of $6 \mathrm{~m} \times 30 \mathrm{~m}\left(180 \mathrm{~m}^{2}\right)$ benthic landscape orthophotomosaic with zoomed in inset, and (B) digital elevation model, for study site Cabrillo National Monument 3 (CNM 3). 


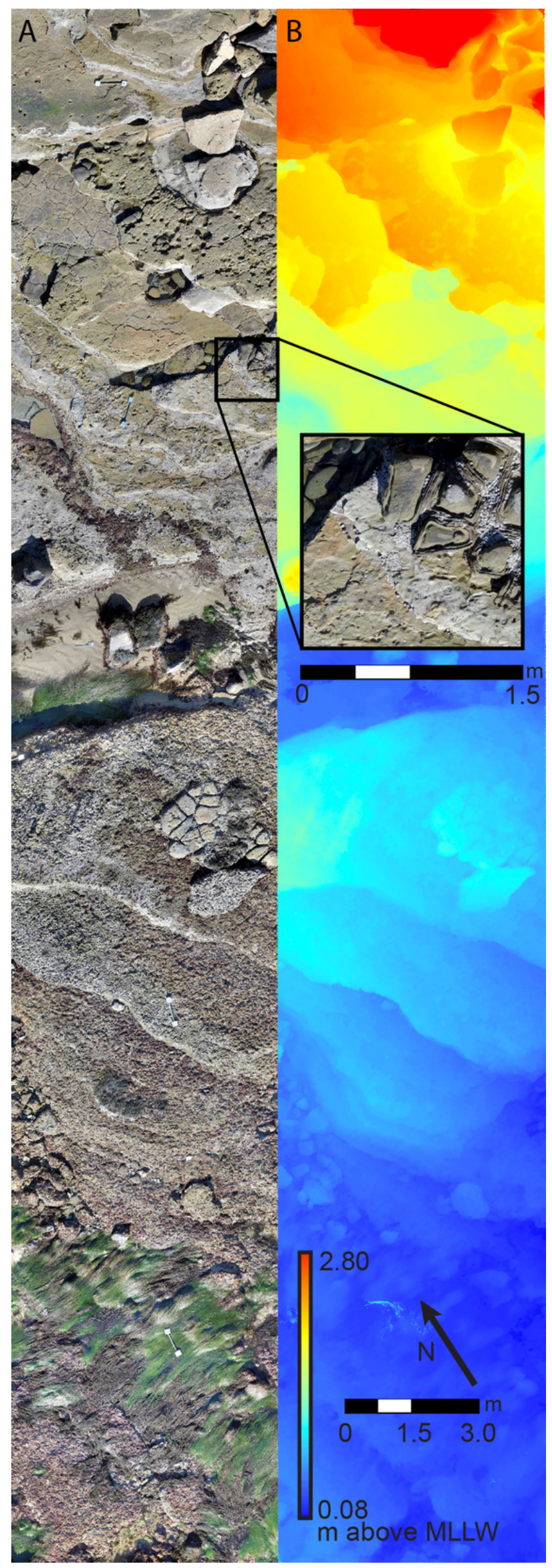

PeerJ reviewing PDF | (2019:07:39678:1:1:NEW 30 Mar 2020) 


\section{Figure 3}

Intertidal area changes with sea-level rise.

Site and zone level intertidal habitat area under $0-2.0 \mathrm{~m}$ of sea-level rise at survey sites (A) Scripps Coastal Reserve (SCR 0), (B) Cabrillo National Monument 1 (CNM 1), (C) Cabrillo National Monument 2 (CNM 2), and (D) Cabrillo National Monument 3 (CNM 3). (E) site and zone level intertidal area change (\% change) under three sea-level rise scenarios. 


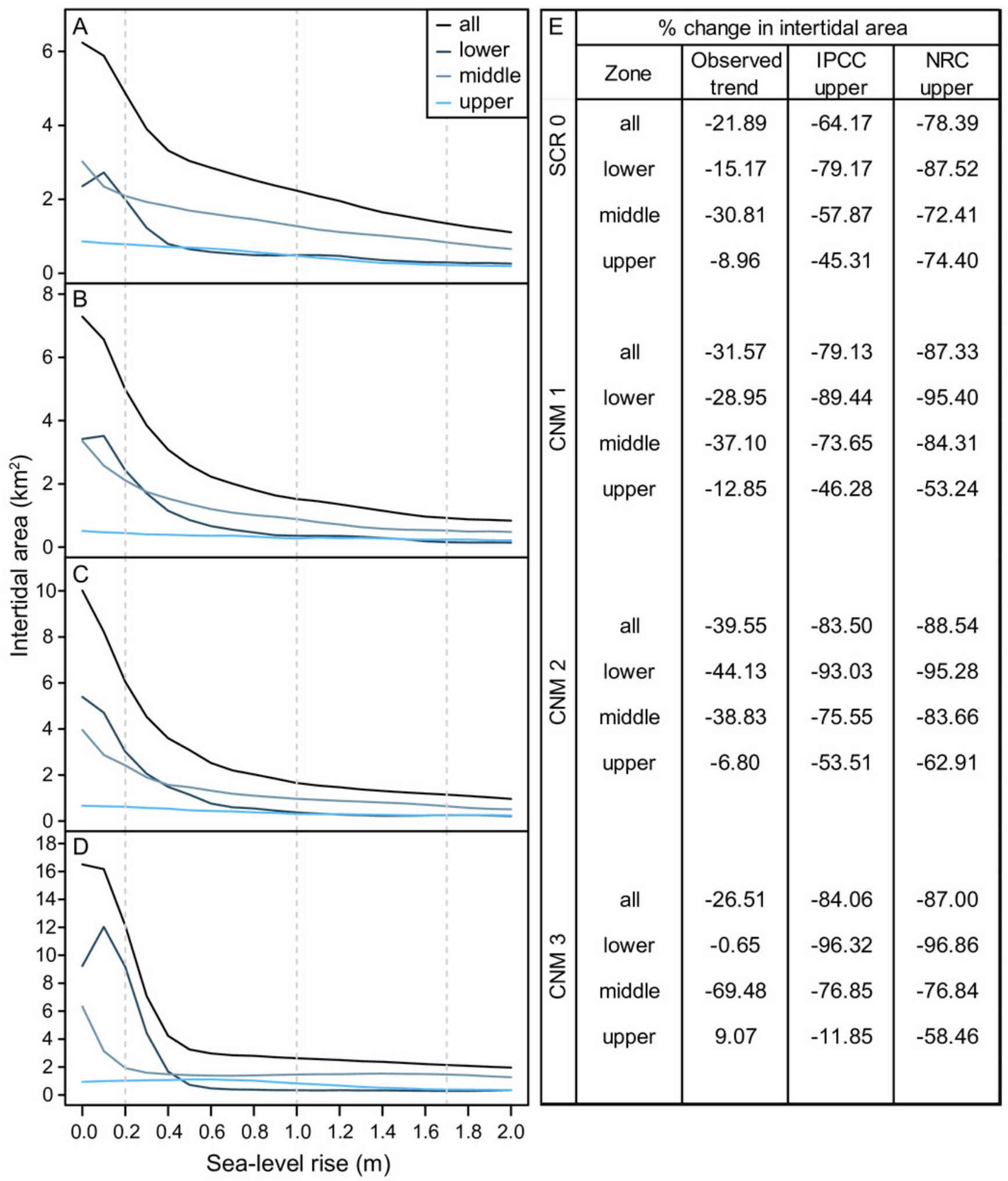


Figure 4

Sea-level rise impacts to area of benthic species.

Estimated current and future areal extent for benthic space occupiers at survey sites (A) Scripps Coastal Reserve (SCR 0), (B) Cabrillo National Monument 1 (CNM 1), (C) Cabrillo National Monument 2 (CNM 2), and (D) Cabrillo National Monument 3 (CNM 3), under 0 - 2.0 $\mathrm{m}$ of sea-level rise, showing decreases for all benthic space occupiers. 


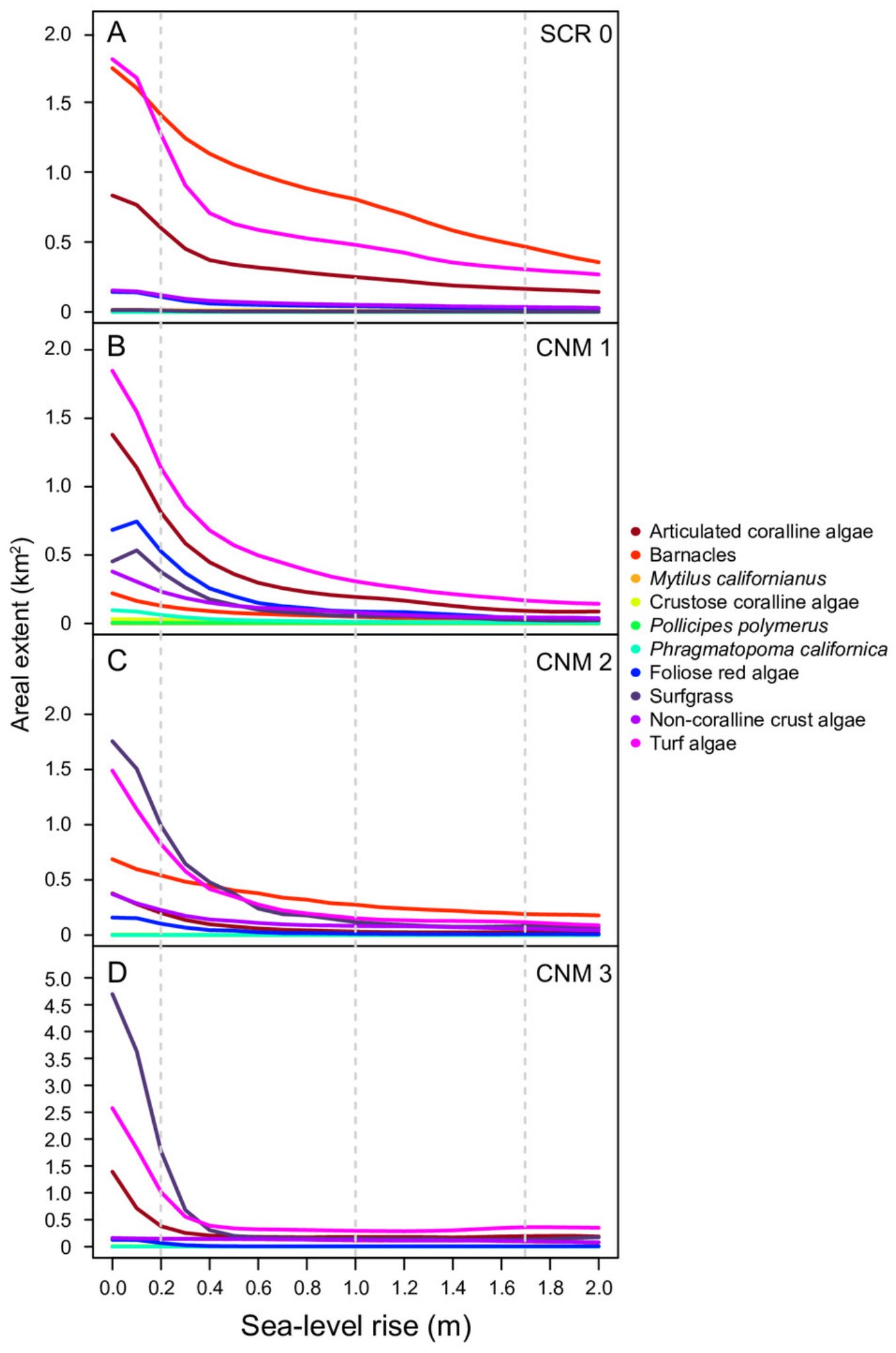


Figure 5

Sea-level rise impacts to rocky intertidal invertebrate abundances.

(A - I) Estimated current and future abundances for focal invertebrates at survey sites Scripps Coastal Reserve (SCR 0) and Cabrillo National Monument 1-3 (CNM 1-3) under 0 - 2.0 m sealevel rise. 

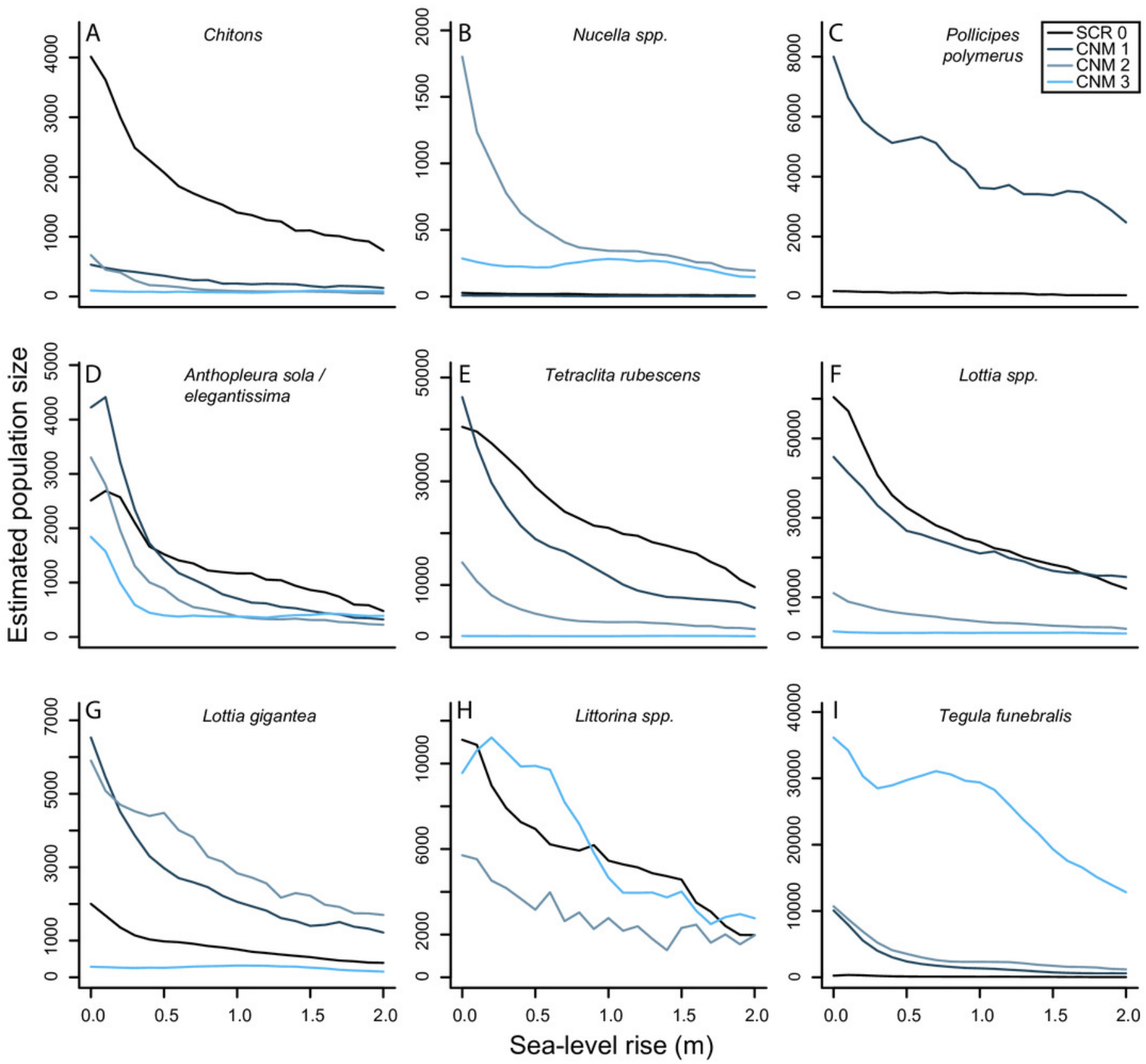